\title{
EXTRATORES DE FÓSFORO EM SOLOS DA AMAZÔNIA TRATADOS COM FERTILIZANTES FOSFATADOS ${ }^{(1)}$
}

\author{
E. C. BRASIL ${ }^{(2)} \&$ T. MURAOKA ${ }^{(3)}$
}

\begin{abstract}
RESUMO
Com o objetivo de avaliar a disponibilidade de fósforo em amostras de solos representativos da Amazônia, desenvolveu-se um experimento em casa de vegetação do Centro de Energia Nuclear na Agricultura, Piracicaba (SP), de outubro de 1993 a março de 1994, utilizando-se amostras da camada superficial de cinco solos (LAmédio, LA-argiloso, LA-muito argiloso, PV-argiloso e PV-muito argiloso). Foram usados, como fontes de $P$, superfosfato triplo, termofosfato yoorin em pó, termofosfato yoorin semi-acabado e fosfato natural da Carolina do Norte, nas doses de $P$ equivalentes a 0, 40, 80 e $120 \mathrm{mg} \mathrm{kg}^{-1}$ de solo. Caupi e arroz foram usados como plantas-testes, e os resultados de produção de matéria seca e de $P$ acumulado na parte aérea foram correlacionados com os de teores de $\mathbf{P}$ nas amostras de cada solo. A extração de $\mathbf{P}$ foi efetuada por meio dos métodos da resina trocadora de ânions, Mehlich-1, Mehlich-3 e Bray-I. Os resultados obtidos demonstraram que o extrator Mehlich-1 extraiu grandes quantidades de fósforo nos tratamentos com fosfato natural da Carolina do Norte. Independentemente da fonte de fósforo utilizada, o extrator Mehlich-3 apresentou as melhores correlações com o caupi e o arroz. Os extratores Mehlich-3 e Bray-I apresentaram maior sensibilidade às variações de solo. 0 extrator Mehlich-3 mostrou-se adequado na avaliação da disponi bilidade de fósforo para as plantas, em diferentes condi ções de solos e fontes de fósforo.
\end{abstract}

Termos de indexação: extratores de fósforo, fosfatos, Mehlich-3, Mehlich-1, Bray-I, resina, Amazônia.

\section{SUMMAR: PHOSPHORUS EXTRACTANTS IN AMAZONIAN SOILS AMENDED WITH PHOSPHATE FERTILIZERS}

Aiming to evaluate the phosphorus availability in fiveAmazonian soil samples, amended with different phosphates, a pot trial was carried out under greenhouseconditions at theCentro deE nergia Nuclear na Agricul tura, Piraci caba (SP,Brazi I), from october, 1993 to march, 1994, using thesoils: medium textureYel low Latosol, clayey Yel low Latosol, very clayey Yel low Latosol,

\footnotetext{
(1) Parte da dissertação de mestrado do primeiro autor, apresentada à ESALQ/USP. Trabalho financiado pela FAPESP eAIEA-Projeto BR 7500. Recebido para publicação em outubro de 1995 e aprovado em setembro de 1997.

(2) Pesquisador da EMBRAPA - Centro de Pesquisa Agroflorestal de Amazônia Oriental (CPATU), Caixa Postal 48, CEP 66095-100 Belém (PA).

(3) Pesquisador e Professor do Centro de Energia Nuclear na Agricultura (CENA/USP), Caixa Postal 96, CEP $13400-970$ Piracicaba (SP).
} 


\begin{abstract}
clayey Red-Yellow Podzolic and very clayey Red-Yellow Podzolic. Four phosphate sources were appl ied (triplesuperphosphate, fineyoorin thermophosphate, granular yoorin thermophosphate and N orth Caroline rock phosphate) in the rates of $P$ equival ent at $0,40,80$ and $120 \mathrm{mg} \mathrm{kg}^{-1}$ soil. Thedry matter yied $d$ and theamount of $P$ taken up by cowpea and ricewerecorrelated with the extractable $P$ by anionic exchangeable resin, Mehlich-1, Mehlich- 3 and Bray-I. The results showed that theextractableP by Mehlich-1 was higher in thesoils amended with North Caroline rock phosphate I rrespective to the phosphorus sources used, the Mehlich-3 extractant showed closecorrelation with plant response TheMehlich-3 and Bray-l extractants weremoresensitive to soil variations. The Mehlich-3 extractant was more suitable in predicting the P availability to plants in the different soils and phosphorus sources.
\end{abstract}

Index terms: phosphorus extractants, phosphates, Mehlich-3, Mehlich-1, Bray-I, resina, Amazônia.

\section{INTRODUÇÃO}

Os solos da Amazônia são, na sua maioria, considerados, quimicamente, pobres. Do ponto de vista da fertilidade do solo, os teores dos nutrientes são bastante reduzidos, sendo o fósforo o el emento mais limitanteao desenvol vimento vegetal. Para diagnosticar o grau de disponibilidade do fósforo para as plantas, vários métodos químicos têm sido avaliados para uso em análises de rotina, sendo testados nas mais variadas situações e apresentando resultados que também variam deacordo com as condições a queforam submetidos. Geralmente, tais métodos apresentam diferentes capacidades de extração e nem sempre se correlacionam bem com as quantidades absorvidas pelas plantas.

A maioria dos laboratórios de análise química de solo da Amazônia utiliza o extrator Mehlich-1 para determinação do fósforo do solo, introduzido sem estudos consistentes sobresua eficiência. Essemétodo tem sido um dos menos indicados para sol os argilosos, principal mente onde houve aplicação de fosfatos pouco solúveis em água (Raij, 1978). De acordo com Raij \& Diest (1980), quando são adicionados ao sol o fosfatos de baixa solubilidade, como fosfatos naturais, a utilização de extratores ácidos podeextrair quantidades de fósforo superiores àquelas consi deradas disponíveis, não apresentando boas corr relações com os rendi mentos das culturas.

Algumas características intrínsecas dos próprios extratores podem indicar as condições de solo-cultura mais adequadas para obtenção de sua mai or eficiência. O extrator Bray-I tem sido recomendado para solos que apresentam amplas variações nas propriedades químicas (Kamprath \& Watson, 1980). A resina de troca aniônica tem apresentado resultados satisfatórios em relação a outros extratores. O método fundamenta-se na premissa de simular o comportamento do sistema radicular das plantas na absorção de fósforo do solo (Raij, 1978) e de não promover alterações nas condições químicas naturais do solo (Williams, 1951). Recentemente, o extrator Mehlich-3 foi introduzido para uso em solos ácidos (Mehlich, 1984) etem despertado crescente interesse por pesquisadores na predição da disponibilidade de fósforo. Segundo J ones (1990), esse extrator é considerado adequado para avaliar o $\mathrm{P}$ de solos que, atualmente, estão sendo analisados pelo extrator Mehlich-1. Dentre os métodos de extração ácida, o Mehlich-3 foi consi derado como o mais econômico para análise de terra em laboratório, pela sua capacidade de extrair, simultaneamente, outros nutrientes $(\mathrm{K}, \mathrm{Ca}$, $\mathrm{Mg}, \mathrm{Na}, \mathrm{B}, \mathrm{Cu}, \mathrm{Fe}, \mathrm{Mn}$ e Zn), além de $\mathrm{P}$ (Tran et al., 1990).

Pretendeu-se, neste trabalho, avaliar a disponibilidade de fósforo em amostras de solos da Amazônia, tratados com fosfatos de diferentes solubilidades, pela comparação da eficiência de métodos quími cos de extração.

\section{MATERIAL E MÉTODOS}

Em cinco local idades do Estado do Pará, coletaramse amostras da camada superficial $(0-20 \mathrm{~cm})$ de solos classificados como latossolo amarelo textura média (LA m.); latossol o amarel o textura argi losa (LA arg.); latossol oamarel o textura muito argi losa (LA m.arg.); podzólico vermel ho-amarelo textura média/argilosa (PV arg.) e podzólico vermel ho-amarelo textura argilosa/muito argilosa (PV m.arg.). Após a coleta, as amostras de solos foram secas ao ar e passadas em peneira com mal ha de $4 \mathrm{~mm}$. Decada amostra, retirouse uma subamostra para caracterização física (Embrapa, 1979) e química (Raij \& Quaggio, 1983), estando os resultados no quadro 1.

No experimento, desenvolvido em casa de vegetação do Centro de Energia Nuclear na Agricultura (CENA/USP), foram empregadas quatro fontes de fósforo, nas doses de 0, 40, 80 e $120 \mathrm{mg} \mathrm{kg}^{-1}$ deP nosolo. Os fosfatos utilizados foram: superfosfato triplo (SFT), termofosfato magnesiano semi-acabado (yoorin-granular), termofosfato magnesiano em pó (yoorin-fino) e fosfato natural da Carolina do Norte (FNCN). Utilizou-se o delineamento experimental em blocos casualisados, com três repetições, em arranjo fatorial $5 \times 4 \times 4$, correspondendo a cinco solos, quatro fontes e quatro doses de P. Utilizaram-se amostras de $3,5 \mathrm{~kg}$ de solo, acondicionadas em vasos de plásticos com capacidade para 4 litros. Adicionou-se cal cário 
Quadro 1. Características físicas e químicas das amostras de solo na profundidade de $0-20 \mathrm{~cm}$

\begin{tabular}{lccccc}
\hline \multirow{2}{*}{ Características } & \multicolumn{5}{c}{ Solo } \\
\cline { 2 - 6 } & $\begin{array}{c}\text { LA } \\
\text { med. }\end{array}$ & $\begin{array}{c}\text { LA } \\
\text { arg. }\end{array}$ & $\begin{array}{c}\text { LA m. } \\
\text { arg. }\end{array}$ & $\begin{array}{c}\text { PV } \\
\text { arg. }\end{array}$ & $\begin{array}{c}\text { PV m. } \\
\text { arg. }\end{array}$ \\
\hline Areia grossa, g kg & 210 & 340 & 70 & 340 & 240 \\
Areia fina, $\mathrm{g} \mathrm{kg}^{-1}$ & 520 & 330 & 100 & 320 & 420 \\
Silte, $\mathrm{g} \mathrm{kg}^{-1}$ & 50 & 90 & 120 & 80 & 70 \\
Argila, $\mathrm{g} \mathrm{kg}^{-1}$ & 220 & 240 & 710 & 260 & 270 \\
$\mathrm{M} . \mathrm{O}, \mathrm{g} \mathrm{dm}^{3}$ & 24 & 24 & 40 & 27 & 25 \\
$\mathrm{pH}\left(\mathrm{CaCl}_{2}\right)$ & 4,0 & 3,5 & 3,5 & 3,2 & 3,8 \\
$\mathrm{Ca}{ }^{2+}, \mathrm{mmol}_{\mathrm{c}} \mathrm{dm}^{-3}$ & 10 & 5 & 10 & 4 & 8 \\
$\mathrm{Mg}^{2+}, \mathrm{mmol}_{\mathrm{c}} \mathrm{dm}^{3}$ & 3 & 2 & 8 & 1 & 2 \\
$\mathrm{~K}^{+}, \mathrm{mmol}_{\mathrm{c}} \mathrm{dm}^{3}$ & 1,7 & 1,1 & 1,1 & 0,7 & 0,9 \\
$\mathrm{P}, \mathrm{mg} \mathrm{dm}^{3}$ & 2 & 5 & 9 & 4 & 4 \\
$\mathrm{Al}^{3+}, \mathrm{mmol}_{\mathrm{c}} \mathrm{dm}^{3}$ & 6 & 12 & 15 & 22 & 8 \\
$\mathrm{H}^{+}+\mathrm{Al}^{3+}, \mathrm{mmol}_{\mathrm{c}} \mathrm{dm}^{3}$ & 42 & 58 & 98 & 121 & 47 \\
\hline
\end{tabular}

dolomítico, com as seguintes características: $208 \mathrm{~g} \mathrm{~kg}^{-1}$ de $\mathrm{CaO} ; 124,8 \mathrm{~g} \mathrm{~kg}^{-1}$ de $\mathrm{MgO}$ e PRNT $104 \%$. As quantidades de calcário foram calculadas com base no critério de el evação da saturação por bases a $40 \%$, ficando, em incubação, por um período de 15 dias, com a umi dade do sol o mantida a, aproximadamente, $60 \%$ da capacidade máxima de retenção de áqua, por meio de pesagens periódicas dos vasos eadição deágua por rega. Após a incubação, realizou-se a aplicação dos fosfatos com base noteor de $\mathrm{P}_{2} \mathrm{O}_{5}$ total decada produto (Brasil, 1988).

Procedeu-sea semeadura docaupi, cultivar Poty/CNC 1371, distribuindo-se dez sementes por vaso, desbastando-se, posteriormente, para três plantas. Na ocasião, inocularam-se as sementes com uma mistura de estirpes de Rhizobium (CN-1525, CN-1527, CN-1545), pelo embebimento das sementes em meio líquido. O caupi foi cultivado por 52 dias e, ao final do período, efetuou-se a colheita, com corte da parte aérea das plantas. Cultivou-se arroz, variedade IAC- 25, por 46 dias, deixando-se, após desbaste, oito plantas por vaso. Antes da semeadura do arroz, micronutrientes foram misturados às amostras de solo, em sol ução contendo, em $\mathrm{mg} \mathrm{dm}^{-3}$, o equival ente a 1,0 de B; 1,0 de $\mathrm{Cu}$; 0,1 de Mo e 2,5 de Zn, nas formas de ácido bórico, sulfato de cobre, molibdato de amônio e sulfato de zinco, respectivamente. Nitrogênio e potássio foram aplicados na forma de uréia e cloreto de potássio, dissolvidos em água, nas quantidades de 200 e $250 \mathrm{mg}$ do nutriente por vaso, respectivamente. A aplicação foi parcelada em duas vezes: a primeira, cinco dias após a germinação, ea segunda, com intervalo de dez dias. O material obtido de caupi e de arroz, após secagem em estufa, a, aproximadamente, $65^{\circ} \mathrm{C}$, foi pesado, moído e submetido à digestão por via úmida (Sarruge \& Haag, 1974), para posterior determinação da concentração de $P$ no tecido vegetal.

Realizaram-se duas amostragens de solo: a primeira, antes da semeadura do caupi, e a segunda, antes da semeadura do arroz, retirando-se, de cada vaso, subamostras para extração de $\mathrm{P}$, mediante os métodos: Mehlich-1(Nelson et al., 1953 e Vettori, 1969), Mehlich-3 (Mehlich, 1984), Bray-I (Bray \& Kurtz, 1945) e resina trocadora aniônica (Raij \& Quaggio, 1983).

Para avaliar a disponibilidade de fósforo, fez-se o cálculo de correlação linear entre a produção de matéria seca e P acumulado na parte aérea do caupi e do arroz e os teores de $\mathrm{P}$ extraído das amostras de solo, considerando-seas fontes eos solos, isol adamente. Ajustaram-se curvas de regressão para os dados de produção de matéria seca da parte aérea do caupi e do arroz e os teores de $\mathrm{P}$ do solo, para cada método, considerando-se todos os solos e fontes utilizadas. Realizaram-se, ainda, correlações lineares simples entre os teores de P extraído dos sol os pelos diferentes extratores, nas duas amostragens.

\section{RESULTADOS E DISCUSSÃO}

\section{Correlação entre o P nas amostras de solo e a resposta das plantas nas diferentes fontes}

No quadro 2, são apresentados os coeficientes de correlação linear, obtidos entre o P extraído por diferentes extratores com a produção de matéria seca e o P acumulado na parte aérea do caupi e do arroz, para os fosfatos utilizados. Observou-se que o uso de diferentes fosfatos influenciou, significativamente, os resultados, principalmente para os parâmetros referentes ao caupi.

Nos solos com SFT, observaram-se el evados coeficientes de correlação para todos os extratores, em ambos os cultivos, indicando que, nessas condições, qualquer um dos métodos avaliados pode ser usado, satisfatoriamente, concordando com Kaminski (1983).

Para o fosfato natural da Carolina do Norte, os coeficientes passaram a refletir o comportamento específico dos métodos. Observou-se que a solução de Mehlich-3 apresentou boa sensibilidade na extração de $\mathrm{P}$ em solos com resíduos de fosfatos de origem apatítica. Esses resultados parecem confirmar as observações de M ehlich (1984), que atribuiu ao ácido acéti co uma solubilização mais moderada da apatita, em relação aos ácidos minerais equivalentes, presentes em outros extratores. $O$ extrator Mehlich-1 não apresentou bons coeficientes nos solos tratados com fosfatos de rocha, indicando a el evada capacidade extratora do método, que promoveu a remoção de $\mathrm{P}$ do sol o, sem a devida correspondência com a resposta biológica das plantas. Essa restrição do método tem sido assinalada por alguns autores (Feitosa \& Raij, 1976 e Raij, 1978), observando-se que, nesse caso, o extrator pode remover quantidades de fósforo mai ores que aquelas consideradas disponíveis, superestimando os teores do nutriente no solo.

O extrator Bray-I apresentou os menores coeficientes de correlação entreo $\mathrm{P}$ extraído ea resposta das plantas de caupi, no tratamento com fosfato natural. Tais resultados discordam dos obtidos por Raij \& Diest (1980) e Kaminski (1983), que consideraram 
o método como um dos mais adequados para estimativas do fósforo disponível em solos que receberam fertilização com fosfatos de diferentes naturezas. De acordo com Smith et al. (1957), o extrator Bray-I distingue, com certa facilidade, sol os que foram fertilizados com fosfato natural, daqueles com fosfatos solúveis. Os autores mencionaram, ainda, que as porções do fosfato natural não dissolvidas não foram atacadas pel o extrator. Para os tratamentos com termofosfato yoorin-granular, os extratores Mehlich-1 e Mehlich-3 apresentaram boas correlações com a resposta das plantas de caupi. A baixa eficiência da resina, apresentada nesse caso, pode estar relacionada com a ação extratora do método e com as características do próprio fosfato. Raij et al. (1986) constataram a eficiência da resina em extrair el evadas quantidades de fósforo do solo, a valores de $\mathrm{pH}$ elevado $(6,5$ a 7,0$)$. Esse aspecto podeter favorecido a remoção de grandes quantidades de fósforo do solo, durante o processo de extração, uma vez que o termofosfato magnesiano apresenta reação al calina. Por outro lado, apesar da boa solubilidade do fosfato, sua granulometria pode ter dificultado a imediata absorção de fósforo pelas raízes das plantas de caupi, ocasionando a baixa correlação com as quantidades extraídas do solo.

Com relação aos coeficientes obtidos entreo $\mathrm{P}$ extraído e os parâmetros das plantas de arroz (Quadro 2), observou-se, demodo geral, uma mel horia na eficiência dos métodos, para os diferentes fosfatos estudados, principalmente nos casos em que houve baixas correlações, no primeiro cultivo. Esses resultados indicam que, havendo maior tempo de reação do fertilizante com o solo, os extratores apresentam maior eficiência na extração de $P$ em relação às quantidades absorvidas pelas plantas.

\section{Correlação entre o P nas amostras de solo e a resposta das plantas nos diferentes solos}

Para avaliar a sensibilidade dos métodos de extração aos sol os utilizados, os dados foram agrupados por tipo de sol o e as correl ações encontram-se no quadro 3.

Os coeficientes obtidos para os parâmetros docaupi demonstraram a sensibilidade dos extratores Mehlich3 e Bray-I às variações de solos. Alguns autores têm demonstrado a adequação do extrator Mehlich-3 em sol os com diferentes características. Lins \& Cox (1989), avaliando o efeito de algumas propriedades de sete sol os de cerrado, verificaram que o extrator Mehlich-3 foi superior ao Bray-I e resina. Piha (1993), comparando o extrator Mehlich-3 à resina, em solos de Zimbabwe, observou que as correlações apresentadas pelos dois métodos variaram com a textura do sol o. Entretanto, para o autor, o Mehlich-3 foi considerado mais adequado para uma larga variação de tipos de solos, por ter sido menos influenciado pela textura.

Com relação ao extrator Bray-I , F reireet al . (1979) mencionaram a boa sensibilidade do método a variações de teores de argila. O efeito normalmente citado para esta sensibilidade relaciona-se com a exaustão do extrator por reação com a argila (Pratt \&
Quadro 2. Correlação linear entre os teores de P extraído pelos diferentes métodos e a resposta do caupi e do arroz, em matéria seca e P acumulado, nas fontes de fósforo

\begin{tabular}{|c|c|c|c|c|}
\hline \multirow{3}{*}{ Método } & \multicolumn{4}{|c|}{ Coeficiente de correlação linear (r) } \\
\hline & \multicolumn{2}{|c|}{ Caupi } & \multicolumn{2}{|c|}{ Arroz } \\
\hline & Matéria seca & $P$ acumulado & Matéria seca & $P$ acumula \\
\hline & \multicolumn{4}{|c|}{ Superfosfato triplo } \\
\hline Resina & $0,742 *$ & $0,755^{*}$ & $0,722 *$ & $0,898^{*}$ \\
\hline Mehlich-1 & $0,748^{*}$ & $0,758 *$ & $0,720^{*}$ & $0,901 *$ \\
\hline Mehlich-3 & $0,774 *$ & $0,809 *$ & $0,714^{*}$ & $0,926^{*}$ \\
\hline \multirow[t]{2}{*}{ Bray-I } & $0,751^{*}$ & $0,844^{*}$ & $0,681 *$ & $0,889^{*}$ \\
\hline & \multicolumn{4}{|c|}{ Fosfato natural de Carolina do Norte } \\
\hline Resina & $0,524 *$ & $0,467 *$ & $0,551^{*}$ & $0,582 *$ \\
\hline Mehlich-1 & $0,540 *$ & $0,521 *$ & $0,653^{*}$ & $0,739 *$ \\
\hline Mehlich-3 & $0,736^{*}$ & $0,700 *$ & $0,684^{*}$ & $0,797 *$ \\
\hline Bray-I & $0,236^{\text {n.s. }}$ & $0,201^{\text {n.s. }}$ & $0,757 *$ & $0,871^{*}$ \\
\hline
\end{tabular}

Termofosfato yoorin-granular

$\begin{array}{lllll}\text { Resina } & 0,305^{*} & 0,256^{*} & 0,609^{*} & 0,697^{*} \\ \text { Mehlich-1 } & 0,753^{*} & 0,728^{*} & 0,683^{*} & 0,767^{*} \\ \text { Mehlich-3 } & 0,705^{*} & 0,690^{*} & 0,716^{*} & 0,797^{*} \\ \text { Bray-I } & 0,568^{*} & 0,547^{*} & 0,679^{*} & 0,759^{*}\end{array}$

Termofosfato yoorin-fino

$\begin{array}{lllll}\text { Resina } & 0,683^{*} & 0,680^{*} & 0,627^{*} & 0,683^{*} \\ \text { Mehlich-1 } & 0,790^{*} & 0,737^{*} & 0,716^{*} & 0,836^{*} \\ \text { Mehlich-3 } & 0,825^{*} & 0,828^{*} & 0,741^{*} & 0,875^{*} \\ \text { Bray-I } & 0,826^{*} & 0,785^{*} & 0,750^{*} & 0,867^{*}\end{array}$

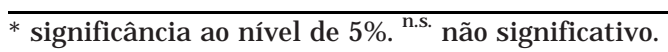

Garber, 1964). O extrator Mehlich-1 apresentou baixas correlações com os parâmetros das plantas de caupi, - que parece estar relacionado com a el evada capacidade de extração de fósforo do método, mesmo em situações em queas plantas mostram dificul dades em absorver o el emento. Para a maioria dos solos, a resina apresentou coeficientes com valores intermediários entre os extratores estudados, situando-se logo abaixo do Mehlich-3 e do Bray-I e acima do Mehlich-1. Situação semel hante foi observada por Kaminski (1983), cujos coeficientes obtidos pela resina foram também inferiores aos do Bray-I e superiores aos do Mehlich-1. Contudo, Raij (1978), após ampla revisão, considerou que o método da resina adequa-se bem para diferentes condições de solo. As correlações obtidas no cultivo do arroz (Quadro 3) demonstraram que, para a maioria dos solos, houve aumento dos coeficientes, da primeira para a segunda amostragem, indicando que, em estudos dessa natureza, há necessidade que seja estabelecida maior interação do fósforo com o solo, para seobter maior eficiência dos métodos de extração. 
Quadro 3. Correlação linear entre os teores de P extraído pelos diferentes métodos e a resposta do caupi e do arroz, em matéria seca e $\mathbf{P}$ acumulado, nos solos utilizados

\begin{tabular}{|c|c|c|c|c|}
\hline \multirow{3}{*}{ Método } & \multicolumn{4}{|c|}{ Coeficiente de correlação $(r)$} \\
\hline & \multicolumn{2}{|c|}{ Caupi } & \multicolumn{2}{|c|}{ Arroz } \\
\hline & Matéria sec & acumulado & Matéria sec & $P$ acumulado \\
\hline & \multicolumn{4}{|c|}{ Latossolo amarelo argiloso } \\
\hline Resina & $0,877 *$ & $0,887^{*}$ & $0,632 *$ & $0,688^{*}$ \\
\hline Mehlich-1 & $0,707^{*}$ & $0,675^{*}$ & $0,624^{*}$ & $0,682 *$ \\
\hline Mehlich-3 & $0,827^{*}$ & $0,947 *$ & $0,795^{*}$ & $0,911^{*}$ \\
\hline \multirow[t]{2}{*}{ Bray-I } & $0,747 *$ & $0,835 *$ & $0,706^{*}$ & $0,841 *$ \\
\hline & \multicolumn{4}{|c|}{ Latossolo amarelo muito argiloso } \\
\hline Resina & $0,374 *$ & $0,439 *$ & $0,692^{*}$ & $0,729 *$ \\
\hline Mehlich-1 & $0,503^{*}$ & $0,553 *$ & $0,794^{*}$ & $0,769 *$ \\
\hline Mehlich-3 & $0,839 *$ & $0,887 *$ & $0,765^{*}$ & $0,874 *$ \\
\hline \multirow[t]{2}{*}{ Bray-I } & $0,846^{*}$ & $0,859 *$ & $0,543^{*}$ & $0,672 *$ \\
\hline & \multicolumn{4}{|c|}{ Latossolo amarelo médio } \\
\hline Resina & $0,694 *$ & $0,765 *$ & $0,592 *$ & $0,607 *$ \\
\hline Mehlich-1 & $0,566 *$ & $0,558 *$ & $0,656 *$ & $0,702 *$ \\
\hline Mehlich-3 & $0,781^{*}$ & $0,890^{*}$ & $0,737^{*}$ & $0,870^{*}$ \\
\hline \multirow[t]{2}{*}{ Bray-I } & $0,663^{*}$ & $0,810^{*}$ & $0,620 *$ & $0,792 *$ \\
\hline & \multicolumn{4}{|c|}{ Podzólico vermelho-amarelo argiloso } \\
\hline Resina & $0,682 *$ & $0,688^{*}$ & $0,693^{*}$ & $0,666^{*}$ \\
\hline Mehlich-1 & $0,209 *$ & $0,207^{\text {n.s. }}$ & $0,481 *$ & $0,430 *$ \\
\hline Mehlich-3 & $0,894 *$ & $0,879 *$ & $0,798^{*}$ & $0,887 *$ \\
\hline \multirow[t]{2}{*}{ Bray-I } & $0,883^{*}$ & $0,938^{*}$ & $0,723^{*}$ & $0,884^{*}$ \\
\hline & \multicolumn{4}{|c|}{ Podzólico vermelho-amarelo muito argiloso } \\
\hline Resina & $0,636^{*}$ & $0,636^{*}$ & $0,618^{*}$ & $0,620^{*}$ \\
\hline Mehlich-1 & $0,414 *$ & $0,400^{*}$ & $0,631 *$ & $0,658 *$ \\
\hline Mehlich-3 & $0,713 *$ & $0,707 *$ & $0,821 *$ & $0,899 *$ \\
\hline Bray-I & $0,841^{*}$ & $0,847 *$ & $0,707^{*}$ & $0,814^{*}$ \\
\hline
\end{tabular}

* significância ao nível de 5\%. ${ }^{\text {n.S. }}$ não significativo.

Correlação entre o P no solo e a produção de matéria seca do caupi e do arroz, considerando todos os solos, fontes e doses

As figuras la e 1b evidenciam uma distribuição bastante dispersa dos pontos, não havendo tendência nítida ao longo da reta ajustada aos dados, indicando que o $\mathrm{P}$ extraído pel os métodos da resina e M ehlich-1 não apresentou boa relação com produção de matéria seca do caupi. Os extratores Mehlich-3 e Bray-I apresentaram as maiores correl ações com as respostas do caupi (Figuras 1c, d), observando-se que a distribuição dos dados mostrou maior agrupamento dos pontos ao longo da reta, permitindo a visualização de uma tendência, o que foi confirmado pelos valores de r. Entretanto, para o extrator Bray-I (Figura 1C), verificou-se um comportamento diferenciado, observando-se um agrupamento acentuado de pontos em uma faixa situada logo abaixo de $5 \mathrm{mg} \mathrm{kg}^{-1}$ de $P$ no solo, devido, provavelmente, aos baixos teores de $\mathrm{P}$ extraído, nos tratamentos com fosfato natural da
Carol ina do Norte, confirmando os baixos coeficientes do método, apresentados no quadro 2 . No cultivo do arroz (Figuras 2a, b), observou-se maior agrupamento dos pontos obtidos, princi-palmente para os métodos da resina e Mehlich-1, que apresentaram pontos bastante dispersos no primeiro cultivo.

Para avaliar as diferenças entre os coeficientes de correlação obtidos em função de solos, fontes e doses, transformaram-se os valores de r para z e procedeuse a comparação deste pel o testet, ao nível de 5\%, de acordo com Steel \& torrie, 1980 (Quadro 4). Os coeficientes obtidos pelo Mehlich-3 e Bray-I, em relação aos resultados de produção de matéria seca do caupi, foram, significativamente, superiores aos dos demais métodos estudados. O Mehlich-1 apresentou os mais baixos valores de $r$, dentre os extratores apresentados anteriormente, provavelmente em virtude de sua baixa sensibilidade a determinadas condições de solos e fontes. Com relação à produção dematéria seca do arroz, nãose verificaram diferenças significativas entre os coeficientes apresentados, apesar deo Mehlich-3 ter fornecido valor ligeiramente maior. Outros estudos têm evidenciado a eficiência do Mehlich-3 na extração deP do sol o. Tran et al . (1990) verificaram que o extrator foi mais confiável que o Bray-I ell, em solos ácidos com el evada capacidade de retenção de fósforo. Evans \& McGuire (1990) constataram que esse extrator, juntamente com o Mehlich-1, apresentou as melhores correlações, não somente para $\mathrm{P}$, mas também para $\mathrm{K}$, Ca e Mg. Resultados semel hantes foram obtidos por Gascho et al. (1990), tendo o método apresentado maior eficiência.

\section{Correlação linear entre os teores de $\mathrm{P}$ extraído do solo pelos diferentes métodos}

Analisando as correlações lineares obtidas entre os teores de $\mathrm{P}$ pelos diferentes métodos estudados (Quadro 5), observou-se que o Mehlich-3 e o Bray-I foram altamente correlacionados entre si. Apesar de o Bray-I conter duas vezes mais fluoreto que o Mehlich-3, a similaridadedos métodos tem sidorelatada por Wolf \& Baker (1985) e Gascho et al. (1990).

\section{Quadro 4. Comparação dos coefi cientes de correlação obtidos entre matéria seca do caupi e do arroz e P extraído do solo, em função de solos, fontes e doses, a partir de transformação de valores de $r$ para $\mathbf{z}$}

\begin{tabular}{lcclll}
\hline \multirow{2}{*}{ Método } & \multicolumn{2}{c}{ Caupi } & & \multicolumn{2}{c}{ Arroz } \\
\cline { 2 - 3 } \cline { 5 - 6 } & $r$ & $z^{*}$ & & $r$ & z \\
\hline Mehlich-3 & 0,776 & $1,035 \mathrm{~A}$ & & 0,657 & $0,787 \mathrm{~A}$ \\
Bray-I & 0,756 & $0,987 \mathrm{~A}$ & & 0,553 & $0,623 \mathrm{AB}$ \\
Resina & 0,659 & $0,791 \mathrm{~B}$ & & 0,554 & $0,624 \mathrm{AB}$ \\
Mehlich -1 & 0,524 & $0,582 \mathrm{C}$ & & 0,581 & $0,664 \mathrm{~A}$ \\
\hline
\end{tabular}

* Valores de z seguidos pela mesma letra na vertical não diferem estatisticamente entre si, ao nível de 5\% de probabilidade. 

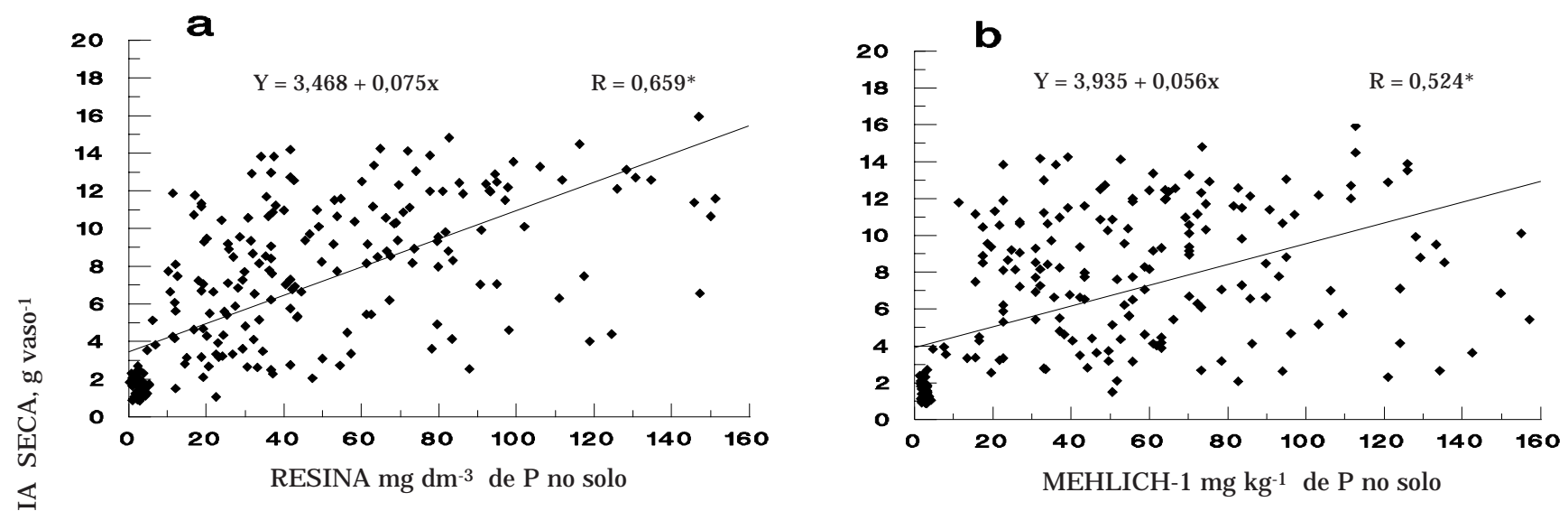

C
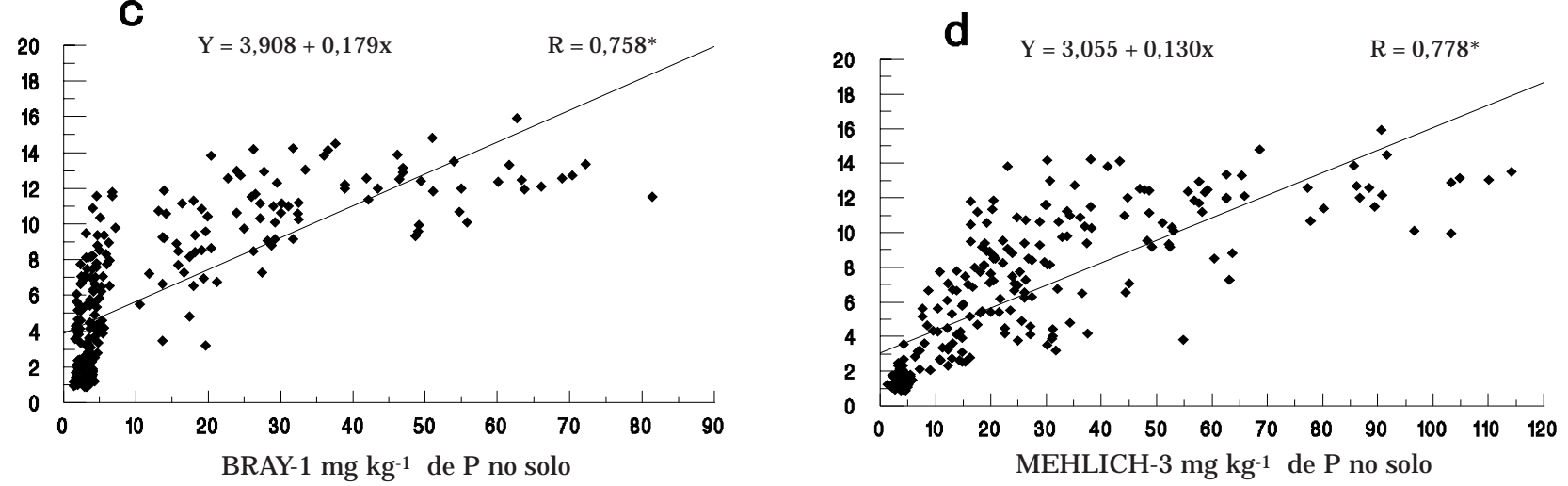

Figura 1. Correlação entre a produção de matéria seca do caupi e os teores de $\mathbf{P}$ do solo, extraídos pelos métodos da resina trocadora de ânions (a), Mehlich-1 (b), Bray-I (c) e Mehlich-3 (d).
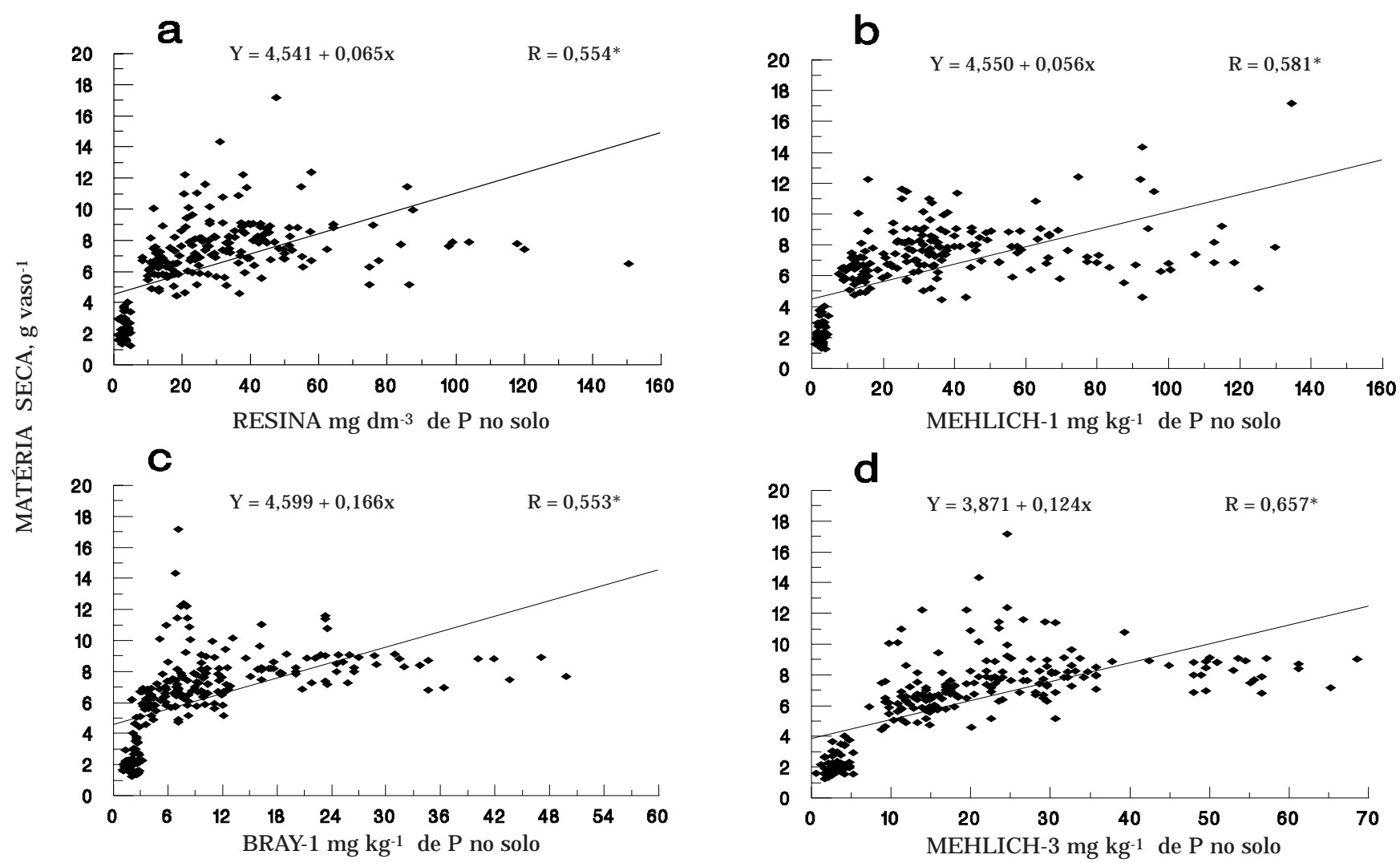

Figura 2. Correlação entre a produção de matéria seca do arroz e os teores de $P$ do solo, extraídos pelos métodos da resina trocadora de ânions (a), Mehlich-1 (b), Bray-I (c) e Mehlich-3 (d). 


\section{Quadro 5. Coeficientes de correlação linear entre as quantidades de $\mathbf{P}$ extraído pelos diferentes extratores, em amostras de solo coletadas na ocasião da semeadura do caupi e do arroz}

\begin{tabular}{lccc}
\hline \multirow{2}{*}{ Método } & \multicolumn{3}{c}{ Coeficiente de correlação $(\mathbf{r})$} \\
\cline { 2 - 4 } & Mehlich-1 & Mehlich-3 & B ray-I \\
\hline \multicolumn{4}{l}{ Amostras coletadas antes da semeadura do caupi } \\
Resina & $0,496 * *$ & $0,623 * *$ & $0,458 * *$ \\
Mehlich-1 & $1,000 * *$ & $0,521 * *$ & $0,308 * *$ \\
Mehlich-3 & $0,521 * *$ & $1,000 * *$ & $0,850 * *$ \\
\multicolumn{4}{l}{ Amostras coletadas antes da semeadura do arroz } \\
Resina & $0,529 * *$ & $0,614 * *$ & $0,441 * *$ \\
Mehlich-1 & $1,000 * *$ & $0,572 * *$ & $0,328 * *$ \\
Mehlich-3 & $0,572 * *$ & $1,000 * *$ & $0,887 * *$ \\
\hline ** significância ao nível de $1 \%$.
\end{tabular}

** significância ao nível de $1 \%$.

Os extratores Bray-I, Mehlich-1 e resina não apresentaram boas correlações entre si, o que deve ser reflexo das diferenças na capacidade extratora de cada método. De acordo com Bahia Filho et al. (1983), essas diferenças têm sido atribuídas à extração preferencial de determinada forma de fósforo, associada à maior atividade da forma preferencialmente extraída. Segundo Barbosa Filho et al. (1987), a forma preferencialmente extraída pela resina é $P$ Al, de onde se pressupõe que esse método deveria correlacionar-se bem com o Bray-I, que também mostra extração preferencial pela mesma forma. Tais explicações não parecem justificar, satisfatoriamente, as diferenças entre os métodos testados. Contudo, Holford (1980) considera que, quanto mais similares forem dois extratores na sua sensibilidade ao tamponamento do solo, maior será a correlação entre ambos.

\section{CONCLUSÕES}

1. I ndependentemente da fonte de fósforo utilizada, o extrator Mehlich-3 apresentou boas correlações com respostas das plantas de caupi e arroz.

2. Os extratores Mehlich-3 eBray-I demonstraram maior sensibilidade às variações de sol o.

3. O extrator Mehlich-3 mostrou-se adequado em predizer a disponibilidade de fósforo para as plantas, em diferentes condi ções de sol os e fontes de fósforo.

4. Na segunda amostragem, houvemaior eficiência dos métodos na extração de $\mathrm{P}$ do solo, indicada pelos coeficientes de correl ação obtidos com os parâmetros do arroz, principalmente nos casos da resina e Melhich-1, que apresentaram baixos coeficientes no primeiro cultivo.

\section{LITERATURA CITADA}

BAHIA FILHO, A.F.C.; BRAGA, J.M.; RIBEIRO, A.C. \& NOVAIS, R.F. Sensibilidade de extratores químicos à capacidade tampão de fósforo. R. bras. Ci. Solo, Campinas, 7:243-249, 1983.

BARBOSA FILHO, M.P.; KINJ O, T. \& MURAOKA, T. Relações entre fósforo "extraível", frações inorgânicas de fósforo e crescimento do arroz em função de fontes de fósforo, calagem e tempo de incubação. R. bras. Ci. Solo, Campinas, 11:147155, 1987.

BRASIL. Ministério da Agricultura. Análise de corretivos, fertilizantes e inoculantes: métodos oficiais. Rio de J aneiro, 1988. 104p.

BRAY, R.H. \& KURTZ, L.T. Determination of total, organic and available forms of phosphorus in soil. Soil Sci., Baltimore, 59:39-45, 1945.

EMPRESA BRASILERIA DE PESQUISA AGROPECUÁRIA. Manual de métodos de análise de solo. Rio deJ aneiro, Serviço Nacional de Levantamento e Conservação do Solo, 1979. n.p.

EVANS, C.E. \& McGUIRE,J .A. Comparison of soil test extractants on Alabama soils. Comm. Soil Sci. Plant Anal., New York, 21:1037-1050, 1990.

FEITOSA, C.T. \& RAIJ , B. van. Influência da natureza de fosfatos aplicados a dois solos no fosfato solúvel em extratores químicos e disponível para trigo e milho. In: CONGRESSO BRASILEIRO DE CIÊNCIA DO SOLO, 15., Campinas, SBCS, 1975. Anais. Campinas, SBCS, 1976. p.215-220.

FREIRE, F.M.; NOVAIS, R.F.; BRAGA, J.M.; FRANÇA, G.E.; SANTOS, H.L. \& SANTOS, P.R.R.S. Adubação fosfatada para a cultura da soja (Glycinemax (L) Merril) baseada no fósforo disponível eno fator "capacidade". R. bras. Ci. Solo, Campinas, 3:105-111, 1979.

GASCHO, G.J . ; GAINES, T.P. \& PLANK, C.O. Comparison of extractants for testing Coastal Plain soils. Comm. Soil Sci. Plant Anal., New York, 21:1051-1077, 1990.

HOLFORD, I.C.R. Effects of phosphate buffer capacity on critical levels and relationships between soil tests and labile phosphate in wheat-growing soils. Austr. J. Soil Res., East Melbourne, 18:405-414, 1980.

J ONES, J.B. Universal soil extractants: their composition and use. Comm. Soil Sci. Plant Anal., New York, 21:1091-1101, 1990.

KAMINSKI, J . Efeito de cinco fosfatos pré, co- e pós-aplicados ao calcário no suprimento de fósforo ao sorgo (Sorghum bicol or (L.) Moench-CV. Conti-Brasil), em três solos ácidos. Piracicaba, Escola Superior deAgricultura "Luiz de Queiroz"/ USP, 1983. 126p. (Tese de Doutorado)

KAMPRATH, E.J . \& WATSON, M.E. Conventional soil and tissue tests for assessing the phosphorus status of soils. In: KHASAWNEH, F.E.; SAMPLES, E.C. \& KAMPRATH, E.J ., eds. The role of phosphorus in agriculture. Madison, American Society of Agronomy, 1980. p.433-469.

LINS, I.D.G. \& COX, F.R. Effect of extractant and selected soil properties on predicting the correct phosphorus fertlization of soybean. Soil Sci. Sco. Am. J., Madison, 53:813-816, 1989.

MEHLICH, A. Mehlich-3 soil test extractant: A modification of Mehlich-2 extractant. Comm. Soil Sci. Plant Anal., New York, 15:1409-1416, 1984. 
NELSON, W.L.; MEHLICH, A. \& WINTERS, E. The development, evaluation and use of soil tests for phosphorus availability. In: PIERRE, W.H. \& NORMAN, A.G., eds. Soil fertilizer phosphorus. New York, Academic Press, 1953. p.153188. (Agronomy, 14)

PIHA, M.I. Evaluation of Mehlich-3 extractant for estimating phosphorus deficiency and phosphorus sorption of Zimbabwean soils. Comm. Soil Sci. Plant Anal., New York, 24:1397-1408, 1993.

PRATT, F.P. \& GARBER, M.J. Correlations for phosphorus availability by chemical tests with inorganic phosphorus fractions. Soil Sci. Soc. Am. Proc., Madison, 28:23-26, 1964.

RAIJ, B. van. Seleção de métodos de laboratório para avaliar a disponibilidade de fósforo em solos. R. bras. Ci. Solo, Campinas, 2:1-9, 1978.

RAIJ, B. van \& DIEST, B. van. Phosphate supplying power of rock phosphate in an Oxisol. Plant Soil, The Hague, 55:97104, 1980.

RAIJ, B. van \& QUAGGIO, J.A. Métodos de análise de solos para fins de fertilidade. Campinas, IAC, 1983. 31p. (Boletim Técnico, 81)
RAIJ, B. van; QUAGGIO, J.A. \& SILVA, N.M. da. Extraction of phosphorus, potassium, calcium and magnesium from soil by an ion-exchange resin procedure. Comm. Soil Sci. Plant Anal., New York, 17:547-566, 1986.

SARRUGE, J.R. \& HAAG, H.P. Análises químicas em plantas. Piracicaba, ESALQ, 1974. 57p.

SMITH, F.W.; ELLIS,B.G. \& GRAVA, J. Use of acid-fluoride solution for the extraction of available phosphorus in calcareous soil and soils which rock phosphate has been added. Soil Sci. Soc. Am. Proc., Madison, 21:400-404, 1957.

STEEL, R.G.D. \& TORRIE, J.H. Principles and procedures of statistics: a biometrical approach. New York, Mc Graw-Hill Book, 1980. 633p.

TRAN, T. S.; GIROUX, M.; GUILBEAUT, J . \& AUDESS, P. Evaluation of Mehlich-III extractant to estimatetheavailable P in Quebec Soils. Comm. Soil Sci. Plant Anal., New York, 21:1-28, 1990.

VETTORI, L. Métodos de análise de solo. Rio de J aneiro, Ministério da Agricultura, 1969. 24p. (Boletim Técnico, 7)

WILLIAMS, E.G. Effects of acid treatment of soils on phosphate availability and solubility. J. Soil Sci., Baltimore, 2:110-117, 1951.

WOLF, A.M. \& BAKER, D.E. Comparison of soil test phosphorus by Olsen, Bray P1, Mehlich-I and Mehlich-III methods. Comm. Soil Sci. Plant Anal., New York, 16:467-484, 1985. 